\title{
Occupational exposures and uncontrolled adult-onset asthma in the European Community Respiratory Health Survey II
}

\author{
Nicole Le Moual, Anne-Elie Carsin, Valérie Siroux, Katja Radon, Dan Norback, \\ Kjell Torén, Mario Olivieri, Isabel Urrutia, Lucia Cazzoletti, Bénédicte Jacquemin, \\ Geza Benke, Hans Kromhout, Maria C. Mirabelli, Amar J. Mehta, Vivi Schlünssen, \\ Torben Sigsgaard, Paul D. Blanc, Manolis Kogevinas, Josep M. Antó and \\ Jan-Paul Zock
}

Affiliations: For a full list of the authors' affiliations please see the Acknowledgements section.

Correspondence: N. Le Moual, Inserm U1018/CESP, Centre for Research in Epidemiology and Population Health, Respiratory and Environmental Epidemiology, 16, avenue Paul Vaillant Couturier, 94807 Villejuif, France. E-mail: nicole.lemoualdinserm.fr

ABSTRACT Occupational exposure is a well-recognised modifiable risk factor for asthma, but the relationship between occupational exposure and asthma control has not been studied. We aimed to study this association among working-age adults from the European Community Respiratory Health Survey (ECRHS).

Data were available for 7077 participants (mean age 43 years, $45 \%$ never-smokers, 5867 without asthma and 1210 with current asthma). Associations between occupational exposure to specific asthmagens and asthma control status (33\% with uncontrolled asthma, based on the Global Initiative for Asthma guidelines) were evaluated using logistic and multinomial regressions, adjusted for age, sex and smoking status, with study areas included as a random effect.

Statistically significant positive associations were observed between uncontrolled adult-onset asthma and both past 12-month and 10-year exposure to any occupational asthmagens (OR (95\% CI) 1.6 (1.0-2.40) and 1.7 (1.2-2.5), respectively); high (1.7 (1.0-2.8) and 1.9 (1.3-2.9), respectively) and low (1.6 (1.0-2.7) and 1.8 (1.2-2.7), respectively) molecular weight agents; and cleaning agents (2.0 (1.1-3.6) and 2.3 (1.4-3.6), respectively), with stronger associations for long-term exposures. These associations were mainly explained by the exacerbation domain of asthma control and no associations were observed between asthmagens and partly controlled asthma.

These findings suggest that occupational exposure to asthmagens is associated with uncontrolled adult-onset asthma. Occupational risk factors should be quickly identified to prevent uncontrolled asthma.

@ERSpublications

Occupational exposure to asthmagens is associated with uncontrolled adult-onset asthma in ECRHS II http://ow.ly/reN8g

This article has supplementary material available from www.erj.ersjournals.com

For editorial comments see page 319 .

Received: Feb 262013 | Accepted after revision: June 282013 | First published online: Aug 152013

Support statement: This study was supported by the Ministry of Education of Spain (grant: SAB2011-0075). Coordination of the occupational asthma component of ECRHS II was supported by grant 1 R01 HL62633-01 of the US NIH/NORA/NHLBI. Co-ordination of ECRHS II was supported by the European Commission (as part of their Quality of Life programme), and from research contract NoFOOD_CT_2004_506378, the Ga ${ }^{2}$ len project and the Global Allergy and Asthma European Network. Sources of funding for the local ECRHS II studies included in this article are listed in the Acknowledgements.

Conflict of interest: Disclosures can be found alongside the online version of this article at www.erj.ersjournals.com

Copyright @ERS 2014 


\section{Introduction}

Studying asthma from a population-based perspective allows a better understanding of the determinants of clinical disease manifestations, including occupational risk factors [1-3]. Despite the importance of the separate concepts of asthma severity, which reflects the intrinsic severity of the disease, and asthma control, which reflects the activity of the disease over a short period, the terminology applied is often used interchangeably and is not standardised [4]. Asthma severity is difficult to define in epidemiology $[4,5]$ and the definitions used are not always adequate [3]. Recent guidelines have moved away from the concept of severity to focus more on asthma control $[3,4]$.

Studies on asthma control have mainly been conducted in clinical studies and few epidemiological studies in large populations have assessed asthma control in a comprehensive manner. Multidimensional scales following Global Initiative for Asthma (GINA) guidelines have been applied to define asthma control in epidemiology in both the European Community Respiratory Health Survey (ECRHS) and the French Epidemiological Study on the Genetics and Environment of Asthma (EGEA) [6-10]. This measure of asthma control on a categorical scale, combining diurnal and nocturnal respiratory symptoms, asthma attacks, activity limitations, lung function and exacerbations, has not been formally validated. However, the classification of asthma control evaluated through GINA expert opinions in clinical settings was similar to scores from specific control questionnaires $[11,12]$. Epidemiological results also support the validity of such a control scale [7]. Few epidemiological studies have evaluated the environmental risk factors of asthma control $[6,8]$. For example, domestic exposures to products in spray form and air pollution have been found to be associated with poorly controlled asthma $[6,9]$.

Occupational exposure to asthmagens, including $>350$ agents specifically identified as disease-related, is a modifiable asthma risk factor implicated in as many as $15 \%$ of cases of adult-onset asthma [1]. Workrelated asthma is commonly classified as occupational asthma caused by exposure to agents at work (appears in adulthood) or work-aggravated pre-existing asthma [2]. In the EGEA survey [5], a strong association was found between occupational exposure to asthmagens and asthma severity in adult-onset asthma. Asthma exacerbation due to work is beginning to receive increased attention [2]. The role of occupational exposures in uncontrolled adult-onset asthma, as assessed through various dimensions of the disease reflecting both acute and chronic activity of the disease, has not been studied.

Based on well-characterised available data in ECRHS for both asthma control [10] and occupational exposure to asthmagens [13], the main objective of the present analysis was to investigate associations between past 12-month and 10-year occupational exposure to specific asthmagens, including both highand low-molecular weight (HMW and LMW, respectively) sensitising agents and irritants, and adult-onset uncontrolled asthma.

\section{Methods}

Study design

The ECRHS is a multicentre general population study (www.ecrhs.org). The baseline study (ECRHS I) was conducted from 1991 to 1993 as described previously [14, 15]. Briefly, a random sample of individuals aged 20-44 years was contacted to complete a short screening questionnaire on respiratory symptoms. In a second step, both a $20 \%$ random sample of the entire group and a respiratory symptom-enriched subgroup (see online supplementary material) were invited to complete a second detailed questionnaire and undergo a clinical examination (lung function tests including spirometry and a nonspecific bronchial reactivity test).

Participants from ECRHS I, from 29 centres in 14 countries, were invited to a follow-up survey (ECRHS II), conducted between 1998 and 2002, and to complete a face-to-face questionnaire (precise information on asthma, respiratory symptoms and occupational history) and a clinical examination (lung function tests and blood samples) $[13,16]$. The information collected included age, smoking status (never, former or current smoker), body mass index (BMI) (overweight: BMI $\geqslant 25 \mathrm{~kg} \cdot \mathrm{m}^{-2}$ ), use of inhaled corticosteroids (ICS), asthma control and sensitisation to common allergens (see online supplementary material). Sensitisation to common allergens was defined as specific serum IgE antibodies to at least one out of four common allergens (house dust mite, cat, timothy grass or Cladosporium herbarum) at a concentration of $\geqslant 0.35 \mathrm{U} \cdot \mathrm{mL}^{-1}$. According to baseline forced expiratory volume in $1 \mathrm{~s}$ (FEV1) based on reference values from QUANJER et al. [17], participants were classified as "with" ( $<80 \%$ predicted values) or "without" low FEV1. Bronchial hyperreactivity (BHR) was defined as a reduction in maximum FEV1 of $\geqslant 20 \%$ of its post-saline value for a methacholine dose of $\leqslant 1 \mathrm{mg}$. The overall response rate for follow-up participation was $\sim 65 \%$. This analysis was limited to participants in ECRHS II from the 26 study centres in 12 countries [10, 13]. The information was used to evaluate both asthma control and occupational exposure among participants ever employed and with available data for sex, age, smoking habits and current asthma $(n=9019)$. After 
excluding 1942 participants, 796 from the enriched sample (all individuals without current asthma) and 1146 from the random sample (with past asthma $(n=167)$ or without current asthma but with asthma symptoms or treatment in ECRHS II $(\mathrm{n}=979)$ ), analysis was performed on 7077 participants (1210 with current asthma and 5867 with never asthma) (fig. 1).

\section{Asthma}

Participants from the random sample were classified as "never asthma" ( $n=5867)$ if they had never reported doctor-diagnosed asthma (at ECRHS I and ECRHS II) or any current asthma-like symptoms (wheezing or whistling without a cold or woken by an attack of shortness of breath), and did not use asthma medications in ECRHS II. Participants were classified as "current asthma" at follow-up ( $\mathrm{n}=1210)$, using previous definitions $[10,18]$, if they had reported doctor-diagnosed asthma and if, in the past 12 months, they had reported respiratory symptoms (wheezing, nocturnal chest tightness, attack of breathlessness following activity, at rest or at night time, or at least one asthma attack) or had used asthma medications in ECRHS II. As previously described by CAZZOLETTI et al. [10], participants with current asthma were classified as: 1) controlled asthma if all the following features were present: diurnal symptoms less than once a week, no nocturnal symptoms, no asthma attacks, short-acting $\beta_{2}$-agonists twice or less per week in the past 3 months, no activity (work or other activities) limitations and no use of oral steroids in the past 12 months and FEV1 $\geqslant 80 \%$ pred; 2 ) partly controlled asthma if one or two of the above features of control were absent; 3) uncontrolled asthma if asthma, shortness of breath or wheezing had caused hospital/ emergency admissions in the past 12 months, oral corticosteroids were used on short courses or continuously in the past 12 months, the subject had $>12$ asthma attacks (more than one a week) in the past 3 months, or more than three of the controlled asthma features listed above were absent (see online supplementary material).

We defined adult-onset asthma as first onset occurring at age $\geqslant 16$ years (see online supplementary material). For analyses including age of onset, 91 participants were excluded due to missing values or inconsistent responses for the two surveys for this variable.

\section{Occupational exposure assessment}

Both past 12-month and 10-year occupational exposures to 22 agents (18 categories of asthmagens classified at high risk for asthma and four categories of a priori "nonasthmagenic" agents [5] classified at low risk for asthma (see online supplementary material)) were assigned through the application of an asthma-specific

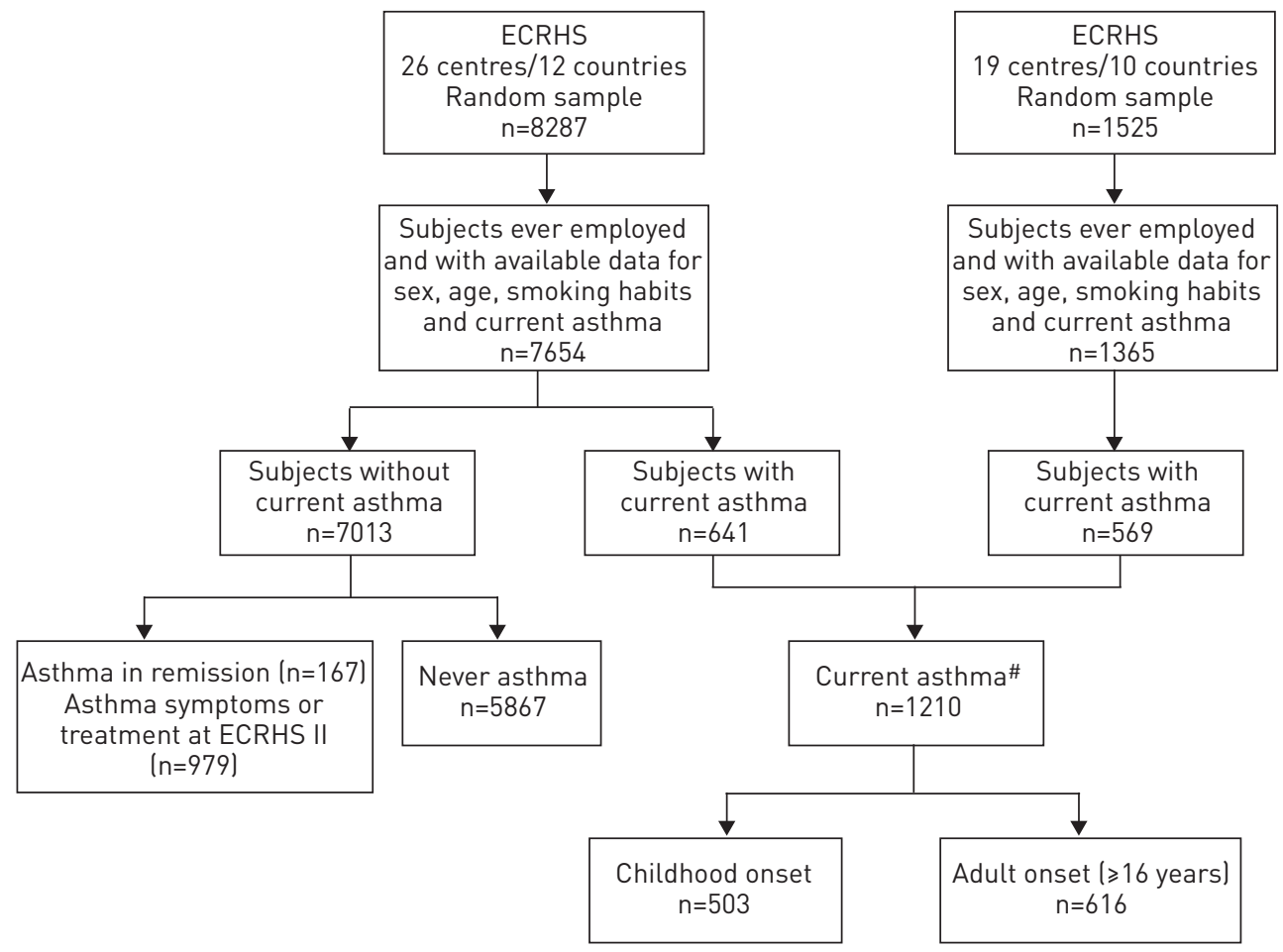

FIGURE 1 Flow chart of the selected population in the European Community Respiratory Health Survey (ECRHS) II.

\#: 91 missing values for age of asthma onset. 
job-exposure matrix (JEM) (cesp.vjf/inserm.fr/asthmajem) [19] followed by an expert re-evaluation step, as described elsewhere [13]. This classification of nonasthmagenic agents [5] may be discussed especially for possible exposure to irritants. Associations between occupational exposures and asthma control were studied for exposure to: 1) any asthmagens; 2) each of the three large groups of asthmagens (HMW agents, LMW agents and mixed exposure or irritant peaks); 3) specific asthmagens when $\geqslant 5 \%$ of participants were exposed (latex, highly reactive chemicals and industrial cleaning chemicals); and 4) nonasthmagenic agents only (nonexposed to asthmagens), with participants classified as nonexposed as the referent category.

\section{Strategy of analysis}

Specific hypotheses have been tested. 1) Uncontrolled asthma is associated with occupational exposure to asthmagens, including exposure to HMW agents, LMW agents and cleaning agents, but not to a priori defined nonasthmagenic agents $[5,19] .2)$ These associations are expected for adult-onset asthma but are unexpected for childhood-onset asthma [5]. Additional analyses were performed to assess the association between occupational exposure and each of the four asthma control domains (lung function, symptoms, exacerbations and activity limitations) $[6,8]$ without including the exacerbation domain in the asthma control definition. To check the consistency of our main reported results, analyses were stratified by BMI, smoking habits, sex and sensitisation to common allergens, as previously suggested [13, 20].

Associations between occupational exposure and asthma control were tested using a multinomial logistic regression. Participants without any history of asthma served as the referent category with controlled, partly controlled and uncontrolled asthma being the nominal outcome category. All associations with $\mathrm{p} \leqslant 0.05$ were deemed statistically significant. Potential heterogeneity among areas (English speaking (UK and USA), northern, central or southern areas in Europe) was evaluated using the Q statistic. All analyses were adjusted for age, sex and smoking status with area included as a random effect [21]. Other additional analyses are described in the online supplementary material.

\section{Results}

The mean age of participants was 43 years, $45 \%$ were never-smokers and $17 \%$ had current asthma (table E1). More females than males reported current asthma, especially for adult-onset asthma $(\mathrm{p}<0.001)$. Females were more likely to be exposed to occupational asthmagens than males $(21.1 \%$ versus $13.4 \%$, respectively, in the past 12 months) (table E1) and especially to cleaning agents ( $8.8 \%$ versus $0.8 \%$, respectively; $\mathrm{p}<0.001)$ while males were more exposed to nonasthmagenic products. Among participants with current asthma, those with childhood-onset asthma were on average younger, with a higher education level, were less often current smokers and had a higher prevalence of sensitisation to common allergens and BHR than those with adult-onset asthma. Among participants with adult-onset asthma, 30\% and 40\% had uncontrolled and partly controlled asthma, respectively (table 1). According to the control definition, participants with exacerbations were always classified as uncontrolled and those with uncontrolled asthma more often used corticosteroids and had more symptoms. Similar trends were observed for childhood-onset asthma (table E2).

For childhood-onset asthma, no associations were observed between asthma control and both past 12-month and 10-year occupational exposure, with OR $<1$ (table 2 and table E3).

For adult-onset asthma, statistically significant associations were observed between past 12-month occupational exposure to any asthmagens, for HMW and LMW asthmagens and cleaning agents, and uncontrolled asthma (table 2). Results were very similar after adjustment for pets at home or for sensitisation to common allergens (not shown). We performed an additional analysis stratified by ICS used. The magnitude of the association between past 12-month asthmagen exposure and uncontrolled asthma was similar when considering ICS users (OR (95\% CI) $1.6(1.0-2.8)$ ) and non-users (1.4 (0.7-2.9)). No association was observed for other specific asthmagens or for a priori nonasthmagenic irritants (at low risk for asthma) and uncontrolled adult asthma (table 2).

Analyses performed between past 10-year occupational exposure and adult-onset asthma control showed stronger associations (table 3). No significant heterogeneity was observed when we performed a metaanalysis by area (fig. 2). Nonetheless, the association between past 10-year occupational exposure to asthmagens and uncontrolled asthma was stronger in three geographic areas (English speaking, northern Europe and central Europe). Similar trends were observed for past 12-month occupational exposure to asthmagens (not shown). Higher odds ratios were observed between occupational exposure to HMW agents and cleaning agents and uncontrolled adult-onset asthma among normal-weight participants and among nonsmokers (fig. E1). Odds ratios were similar in males and females for exposure to HMW agents, but for LMW agents, including industrial cleaning agents, significant associations were observed only in females. Regarding sensitisation to common allergens (fig. E1), a higher odds ratio was observed in sensitised 
TABLE 1 Description of the European Community Respiratory Health Survey II population with asthma according to adult-onset asthma control

\begin{tabular}{|c|c|c|c|c|}
\hline & $\begin{array}{l}\text { Controlled } \\
\text { asthma }\end{array}$ & $\begin{array}{l}\text { Partly controlled } \\
\text { asthma }\end{array}$ & $\begin{array}{l}\text { Uncontrolled } \\
\text { asthma }\end{array}$ & p-value \\
\hline Subjects $n$ & 167 & 217 & 161 & \\
\hline Age years & $43.5 \pm 6.9$ & $43.9 \pm 7.1$ & $44.6 \pm 6.5$ & NS \\
\hline Sensitisation to common allergens ${ }^{\#}$ & $153(56.2)$ & $188(50.0)$ & $138(44.9)$ & NS \\
\hline Total $\lg \mathrm{E}>100 \mathrm{kU} \cdot \mathrm{L}^{-1}$ & 153 (37.3) & $188(38.3)$ & $138(44.9)$ & NS \\
\hline Use of oral corticosteroids in past 12 months $^{+}$ & 0.0 & 3.7 & 23.5 & $<0.001$ \\
\hline Four domains of asthma control $n$ & 167 & 217 & 161 & \\
\hline Lung function $\mathrm{FEV} 1<80 \%$ pred $^{\S}$ & 0.0 & 20.6 & 22.5 & $<0.001$ \\
\hline Symptoms in past 3 months & 0.0 & 54.8 & 86.3 & $<0.001$ \\
\hline Exacerbations in past 12 months & 0.0 & 0.0 & 35.4 & $<0.001$ \\
\hline Activity limitation in past 12 months & 0.0 & 24.0 & 52.8 & $<0.001$ \\
\hline Age finishing full-time education years $n$ & 167 & 217 & 161 & NS \\
\hline$<17$ & 26.4 & 25.3 & 26.7 & \\
\hline $17-20$ & 34.7 & 27.7 & 29.2 & \\
\hline$>20$ & 38.9 & 47.0 & 44.1 & \\
\hline Body mass index $n$ & 166 & 200 & 140 & NS \\
\hline$<25 \mathrm{~kg} \cdot \mathrm{m}^{-2}$ & 45.8 & 45.0 & 38.6 & \\
\hline $25-30 \mathrm{~kg} \cdot \mathrm{m}^{-2}$ & 37.9 & 36.5 & 36.4 & \\
\hline$\geqslant 30 \mathrm{~kg} \cdot \mathrm{m}^{-2}$ & 16.3 & 18.5 & 25.0 & \\
\hline $\begin{array}{l}\text { Have you had to leave jobs (during follow-up) } \\
\text { because it affected your breathing? }\end{array}$ & 163 (3.7) & $212(6.6)$ & $152(14.5)$ & 0.001 \\
\hline Asthma-specific job exposure matrix $n$ & 167 & 216 & 161 & NS \\
\hline Nonasthmagenic irritants in life & 15.6 & 13.9 & 16.8 & \\
\hline
\end{tabular}

Data are presented as $\%, \mathrm{n}(\%)$ or mean $\pm \mathrm{SD}$, unless otherwise stated. Out of 616 participants with adult-onset asthma, 545 were classified as having controlled, partly controlled or uncontrolled asthma ( $n=71$ missing values for asthma control). Participants with current asthma were classified as controlled asthma, partly controlled asthma, or uncontrolled asthma as previously described by CAZZOLETTI et al. [10] and in the Asthma section. BHR: bronchial hyperreactivity; ICS: inhaled corticosteroids; FEV1: forced expiratory volume in 1 s; \% pred: \% predicted; NS: nonsignificant. \#: defined as specific serum $\mathrm{IgE}$ antibodies to at least one out of four common inhalant allergens (house dust mite, cat, timothy grass or Cladosporium herbaruml at concentrations of $\geqslant 0.35 \mathrm{U} \cdot \mathrm{mL}^{-1} ;{ }^{\circ}$ : defined as a reduction in maximum FEV 1 of $\geqslant 20 \%$ of its post-saline value for a methacholine dose of $\leqslant 1 \mathrm{mg}^{+}{ }^{+}$: when needed, continuously, in short courses (Annex E1, question 3); ${ }^{\S}$ : according to baseline FEV1 values based on the reference values of QUANJER et al. [17], participants were classified as "with" $(<80 \%$ pred) or "without" low FEV1.

participants for exposure to HMW agents and in nonsensitised participants for exposure to LMW agents, including industrial cleaning agents. Similar trends were observed for past 12-month occupational exposures (not shown).

When studying the association between occupational exposure and each domain of adult-onset asthma control separately, significant associations were observed only for the exacerbations domain (table 4). In addition, 12-month exposure to HMW agents was significantly associated with adult-onset asthma treated with oral corticosteroids (OR (95\% CI) $2.7(1.1-6.3)$ ). The OR $(95 \%$ CI) were $1.8(0.8-4.0), 0.6(0.1-2.6)$ and $1.1(0.2-4.8)$ for asthmagens, LMW and industrial cleaning agents, respectively. Further analyses were conducted without including the exacerbation domain in the asthma control definition (current clinical control domain) (table 3). Lower odds ratios were observed with nonsignificant associations for 12-month occupational exposure, whereas significant associations were observed for 10-year occupational exposure and uncontrolled asthma for each group of asthmagens.

The population attributable risk for uncontrolled adult-onset asthma for 12-month exposure to asthmagens was $9.4 \%$. 


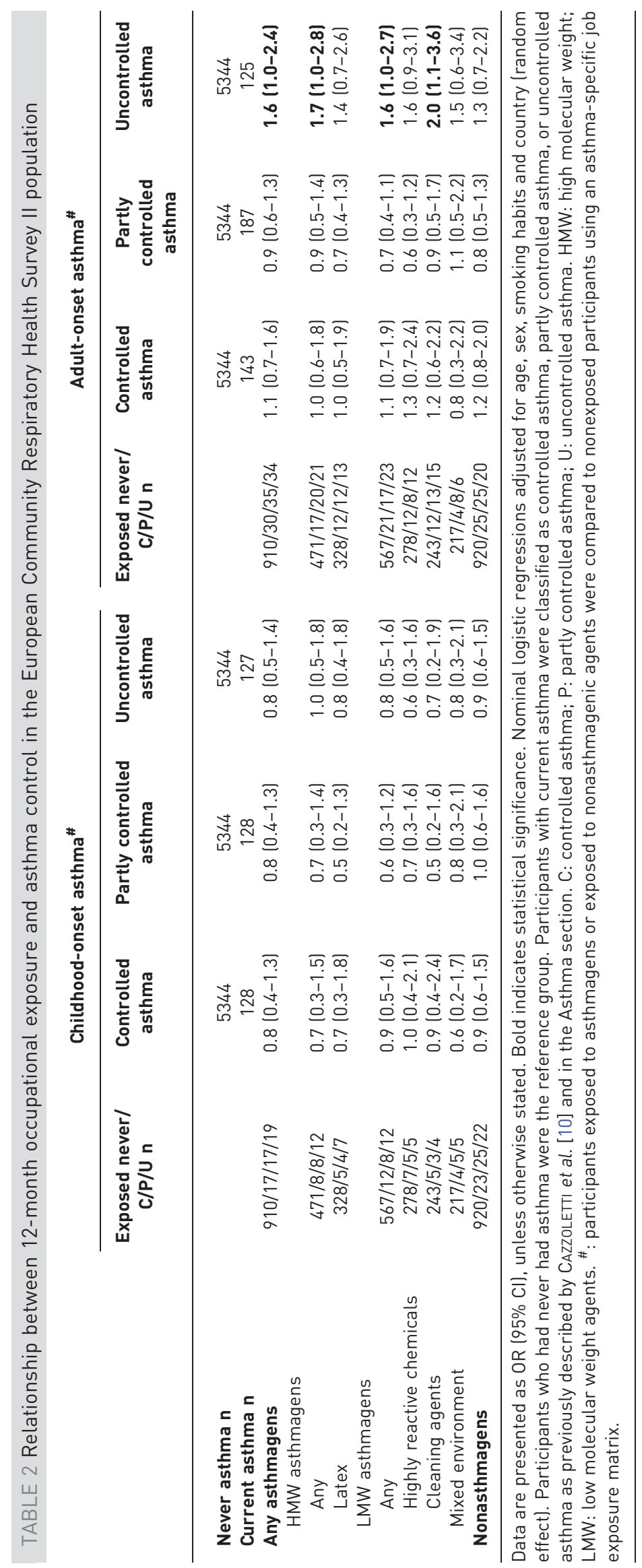




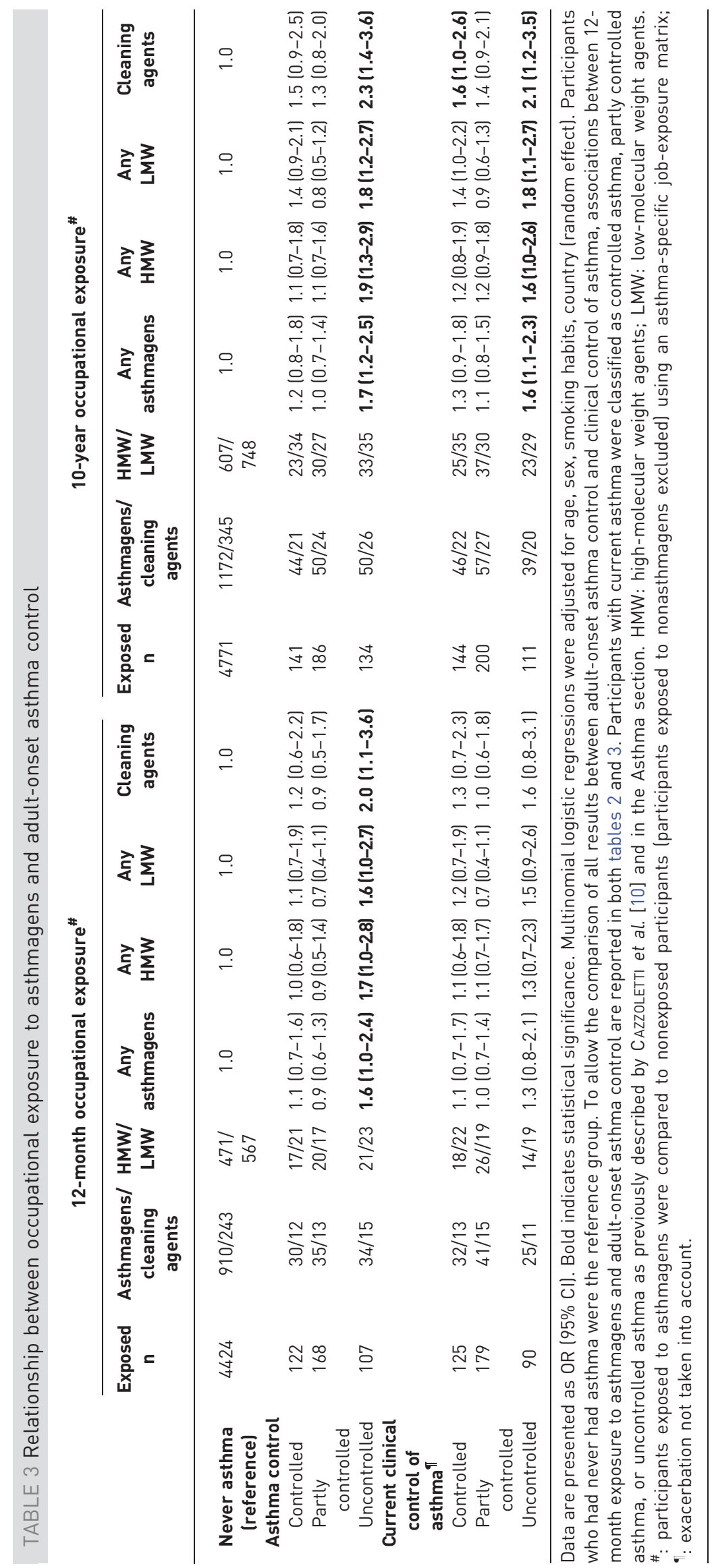




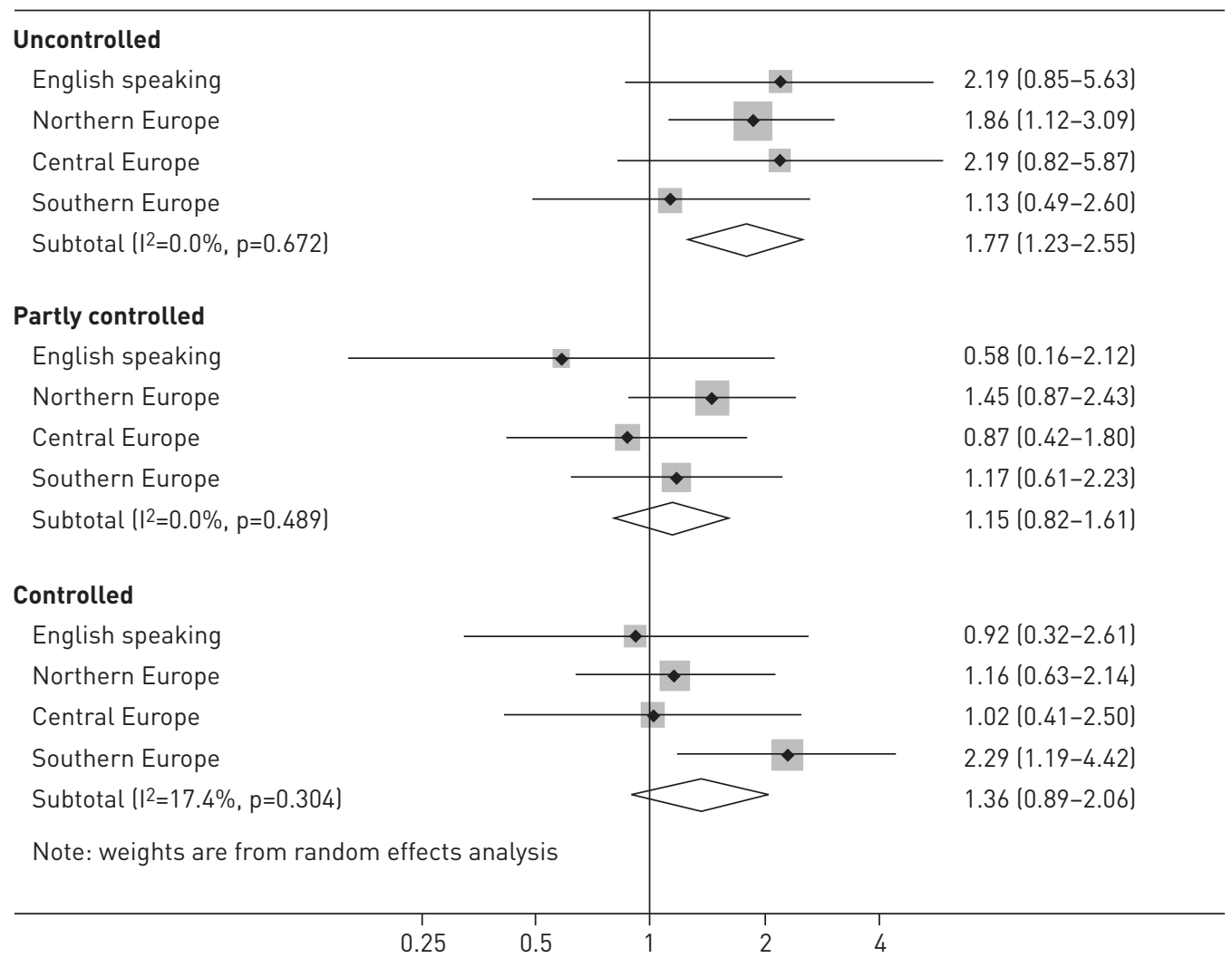

FIGURE 2 Results from meta-analysis by geographical areas: 10-year exposure. Adjusted for age, sex, smoking habits and country (random effect). Participants who had never had asthma were the reference group. Participants exposed to nonasthmagenic agents or exposed to asthmagens were compared to nonexposed participants.

\section{Discussion}

Our study shows that occupational exposure to asthmagens is associated with uncontrolled adult-onset asthma in a large population-based study. The associations were stronger for long-term exposure than for current occupational exposures. The observed associations with uncontrolled asthma were mainly explained by the exacerbations domain of asthma control. Our results suggest that both exposure to sensitisers and irritants are associated with uncontrolled asthma and exacerbations. The population attributable risk of uncontrolled asthma due to past 12-month occupational exposure was found to be $9 \%$, approximately half of the population attributable risk for adult-onset asthma overall [1].

The strengths of our study are the three-level asthma control scale used, which was assessed in a comprehensive manner by integrating several dimensions of the disease, and the assessment of occupational exposure to asthmagens with an asthma-specific JEM. Other strengths are the specificity of the results, the absence of association with a priori nonasthmagenic agents and strong associations for asthmagens with adult-onset asthma.

In ECRHS II, significant associations were found between occupational exposure to dusts, gases and fumes in general (evaluated by the ALOHA JEM) and severe asthma exacerbation [21]. In the present analysis we evaluated occupational exposure to specific asthmagens by an asthma-specific JEM combined with an expert review step $[13,19]$. Re-evaluation by an expert blinded to disease status ensured the objectiveness of the method. To limit misclassification errors, specificity was favoured; a job was classified as exposed to asthmagen only if the probability of exposure was high for an important number of subjects in that job [19]. There is no evidence for recall bias in job history [22], but we are not aware of misclassification errors especially for 10-year exposure. This approach is less prone to bias than self-reported exposures [23] and gives reliable estimates of exposure to asthmagen $[5,13,19]$. The asthma-specific JEM was designed to evaluate exposure to agents causing asthma and may be less appropriate to evaluate exposure to agents aggravating asthma. However, exposures classified at low risk for asthma might be risk factors involved in work-aggravated asthma. In the present analysis, we studied work-related asthma as we cannot distinguish 


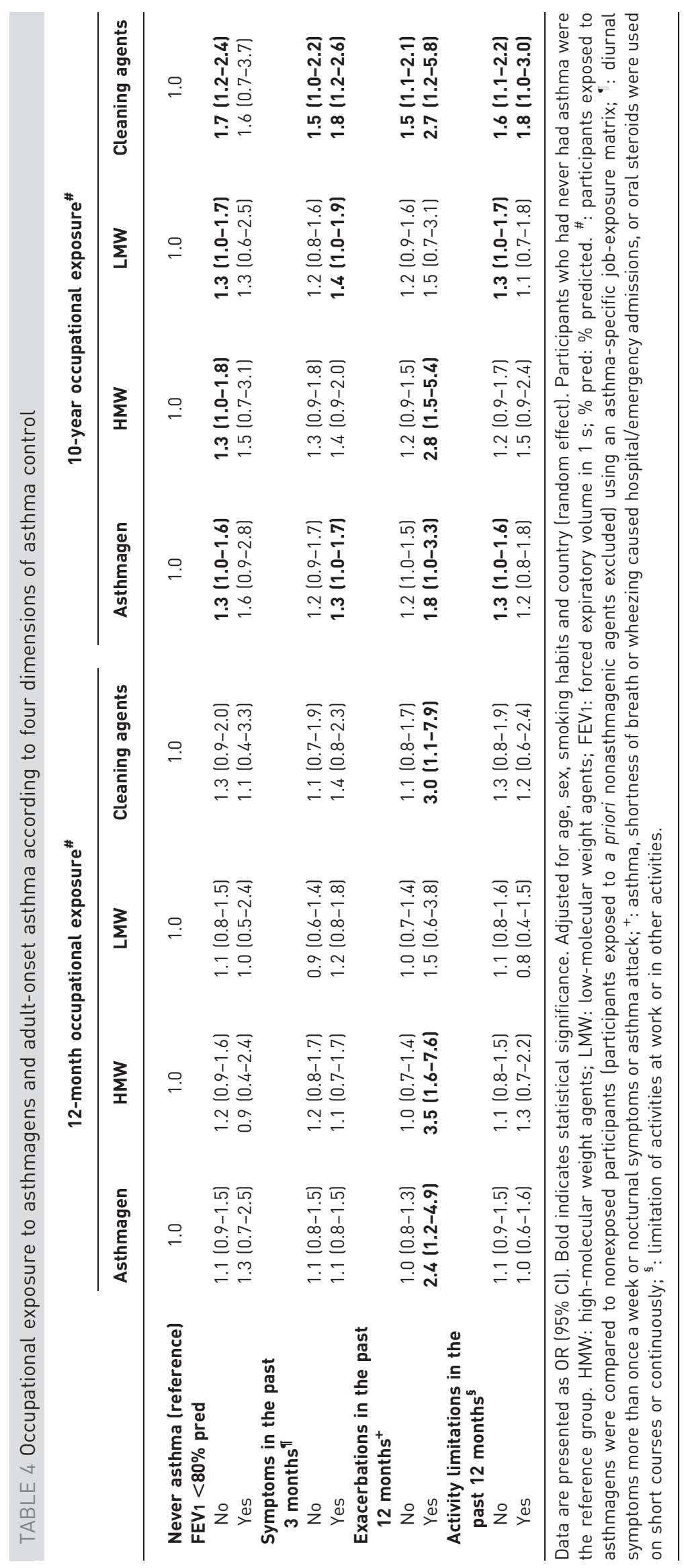


between these two entities (occupational or work-aggravated asthma). The lack of association for childhood-onset asthma, with $\mathrm{OR}<1$, is consistent with the healthy hire worker effect [24]. Furthermore, a recent study suggested that individuals with childhood-onset asthma tend to have a higher education level than those without asthma [25], a finding also observed in our study. As a consequence, those individuals might be less exposed in adulthood, which is consistent with our findings.

Stronger associations were observed for past 10-year than past 12-month occupational exposures for adultonset uncontrolled asthma, a finding consistent with one report in EGEA studying long-term exposure to air pollution [6]. This phenomenon might be due to the fact that persistent exposures to asthmagens may directly induce uncontrolled asthma or a more severe form of the disease [5, 26]. In EGEA, occupational exposure to asthmagens was associated with severe adult-onset asthma but not with mild asthma [5]. Asthma remission is very low in adults, and if the remission does not occur a few years after onset, the disease tends to become chronic [27, 28]. Current adult-onset asthma is related to disability [29]. Most workers who are removed from exposure to the causal agent maintain persistent symptoms and BHR [26]. The prognosis of occupational asthma is improved by early and complete removal from exposure [30]. Therefore, work-related asthma might be more often uncontrolled due to the persistence of exposures. Participants with uncontrolled asthma might currently be at work or exposed less often, because activity limitation was used to evaluate uncontrolled disease. Investigating 10-year occupational exposure reduces this bias but does not entirely eliminate it unless only participants working during the follow-up are studied. Therefore, our results might be underestimated.

We investigate for the first time uncontrolled asthma following GINA guidelines (2006-2010) in association with occupational exposures. However, it could be argued that findings from EGEA may reflect a relationship between occupational exposure and uncontrolled asthma rather than severity, due to limited information regarding asthma activity and treatments in EGEA [5]. In EGEA, cases were recruited from chest clinics where asthma may be more severe than in a general population. Consistent results were observed in both surveys, but odds ratios were much higher, with large confidence intervals, in EGEA [5]. In ECRHS, few subjects were exposed to specific hazards that might have been of interest (flour and diisocyanantes $(<1 \%$ of subjects exposed)), which is a limitation of our analysis. For exposure to cleaning agents, our results are consistent with those observed between domestic exposure to cleaning sprays and poorly controlled asthma [9].

Contrary to associations observed between quality of life or air pollution and asthma control [6, 7], the association observed between asthmagens and partly controlled asthma was not in-between those observed with controlled asthma and uncontrolled asthma. The hypothesis for this absence of trend for asthma control is that the association observed for uncontrolled asthma was mainly due to exacerbations which are not part of the definition of partly controlled asthma. Asthma control consists of two main domains: 1) lack of impairment (absence of symptoms, minimal treatment use, normal activity level and lung function level); and 2) lack of future risk to the patient (absence of asthma exacerbations, prevention of accelerated decline in lung function over time and no side-effects from medications) [4, 11]. It has been suggested that exacerbations should be considered separately from current clinical control because they may occur even if the patient has adequate current control of symptoms and few activity limitations [4]. Asthma exacerbation due to work has not been widely reported; however, this might be a key problem in occupational settings [2]. Our definition of exacerbation includes hospital/emergency admissions and the use of oral corticosteroids in short courses or continuously in the past 12 months [10]. Oral corticosteroid used continuously may also be considered as a marker of asthma severity. In previous studies, exacerbations were defined only by hospitalisation or emergency aspects [31], or in addition to the "use of oral corticosteroids when needed" to evaluate severe exacerbations [21]. In ECRHS both aspects of exacerbations seem to be linked to occupational exposure to asthmagens [21]. More work is needed regarding the standardisation of the definition of asthma exacerbations in epidemiological studies.

A further strength of our analysis is the consistency of our findings. The association between occupational exposure and uncontrolled asthma was not modified by sex, smoking habits, BMI or sensitisation to common allergens, although stronger associations were observed in nonsmokers and in females. Exposure to LMW agents more than doubled the risk of uncontrolled asthma among participants without sensitisation, while exposure to HMW agents doubled the risk among those with sensitisation. These results are consistent with a previous report [32]. Our results suggest that overweight participants are not more susceptible to occupational exposures than those with lower BMI, as previously suggested with air pollution [6]. Associations between occupational exposure to asthmagens and uncontrolled asthma seem to be mainly driven by three geographic areas (English speaking (UK and USA), northern and central Europe), which might partly be due to the heterogeneity of the prevalence of uncontrolled asthma across Europe [10] or to 
regional differences in occupational exposures, medication practices or other unmeasured correlates of geographic area.

The study has potential limitations (cross-sectional study and centres not representative of the country), as previously discussed [10]. Asthma control may be difficult to define in epidemiology, although the validity of such a control scale was supported by epidemiological results [7, 10]. Although all associations between asthmagens (known risk factors for asthma) and uncontrolled asthma were studied according to a priori hypotheses $[5,6,8,13]$, it may be argued that our results regarding specific asthmagens require cautious interpretation due to multiple testing [33].

Our study suggests a strong deleterious effect of occupational exposure to asthmagens in uncontrolled adult-onset asthma. These results are consistent with the hypothesis that occupational exposure to asthmagens can quickly induce uncontrolled asthma [5]. We observed no association with partly-controlled asthma, which is consistent with previous results on asthma severity [5]. Both exposures to LMW and HMW agents and to cleaning agents seem related to uncontrolled asthma. Occupational exposure is a preventable risk factor and the importance of prevention has been recently underlined [21, 30, 34]. Preventing asthma exacerbations, an important asthma control domain $[4,11]$, is essential since severe asthma exacerbations have been related to accelerated decline in lung function [2]. Furthermore, uncontrolled asthma is associated with poorer health-related quality of life [7]. It is important to identify potential occupational risk factors quickly and reduce these exposures as soon as possible to prevent uncontrolled asthma.

\section{Acknowledgements}

The authors' affiliations are as follows. N. Le Moual: Inserm, Centre for Research in Epidemiology and Population Health (CESP), U1018, Respiratory and Environmental Epidemiology, Villejuif and Université Paris Sud, UMRS 1018, Villejuif, France; A-E. Carsin: Centre for Research in Environmental Epidemiology (CREAL), Barcelona, Hospital del Mar Medical Research Institute (IMIM), Barcelona and CIBER Epidemiología y Salud Pública (CIBERESP), Barcelona, Spain; V. Siroux: Inserm, U823, Centre for Research Albert Bonniot, Environmental Epidemiology Applied to Reproduction and Respiratory Health, Grenoble and Université Joseph Fourier, Grenoble, France; K. Radon: Institute for Occupational, Social and Environmental Medicine, Hospital of the Ludwig-Maximilian, University Munich, Munich, Germany; D. Norback: Dept of Medical Sciences, Uppsala University, Uppsala, Sweden; K. Toren: Section of Occupational and Environmental Medicine, Sahlgrenska Academy at University of Gothenburg, Gothenburg, Sweden; M. Olivieri: Unit of Occupational Medicine, University of Verona, Verona, Italy; I. Urrutia: Respiratory Dept, Galdakao Hospital, Galdakao, Spain; L. Cazzoletti: Unit of Epidemiology and Medical Statistics, Dept of Medicine and Public Health, University of Verona, Verona, Italy; B. Jacquemin: Inserm, Centre for Research in Epidemiology and Population Health (CESP), U1018, Respiratory and Environmental Epidemiology, Villejuif; Université Paris Sud, UMRS 1018, Villejuif, France; and Centre for Research in Environmental Epidemiology (CREAL), Barcelona, Spain; G. Benke: Dept of Epidemiology and Preventive Medicine, Monash University, Melbourne, Australia; H. Kromhout: Institute for Risk Assessment Sciences, Environmental Epidemiology Division, Utrecht University, Utrecht, The Netherlands; M.C. Mirabelli: Dept of Epidemiology and Prevention, Division of Public Health Sciences, Wake Forest School of Medicine, Winston-Salem, NC, USA; A.J. Mehta: Swiss Tropical and Public Health Institute, Basel; School of Medicine, University of Basel, Basel, Switzerland; and Dept of Environmental Health, Harvard School of Public Health, Boston, MA, USA; V. Schlünssen: Section of Environment, Occupation and Health, Dept of Public Health, Aarhus University, Aarhus, Denmark; T. Sigsgaard: Section of Environment, Occupation and Health, Dept of Public Health, Aarhus University, Aarhus, Denmark; P.D. Blanc: Division of Occupational and Environmental Medicine, Dept of Medicine, University of California, San Francisco, CA, USA; M. Kogevinas: Centre for Research in Environmental Epidemiology (CREAL), Barcelona; Hospital del Mar Medical Research Institute (IMIM), Barcelona; CIBER Epidemiología y Salud Pública (CIBERESP), Barcelona, Spain; and National School of Public Health, Athens, Greece; J.M. Anto: Centre for Research in Environmental Epidemiology (CREAL), Barcelona; Hospital del Mar Medical Research Institute (IMIM), Barcelona; CIBER Epidemiología y Salud Pública (CIBERESP), Barcelona; and Universitat Pompeu Fabra (UPF), Barcelona, Spain; J-P. Zock: Centre for Research in Environmental Epidemiology (CREAL), Barcelona; Hospital del Mar Medical Research Institute (IMIM), Barcelona; and CIBER Epidemiología y Salud Pública (CIBERESP), Barcelona.

The local ECRHS II studies included in this article were funded by the following bodies. Albacete, Spain: Fondo de Investigaciones Santarias (FIS) (grant codes: 97/0035-01, 99/0034-01 and 99/0034-02), Hospital Universitario de Albacete, Consejeria de Sanidad; Antwerp, Belgium: FWO (Fund for Scientific Research)-Flanders Belgium (grant code: G.0402.00), University of Antwerp, Flemish Health Ministry; Barcelona, Spain: SEPAR, Public Health Service (grant code: R01 HL62633-01), Fondo de Investigaciones Santarias (FIS) (grant codes: 97/0035-01, 99/0034-01 and 99/0034-02), CIRIT (grant code: 1999SGR 00241), Red Respira ISCII; Basel, Switzerland: Swiss National Science Foundation, Swiss Federal Office for Education and Science, Swiss National Accident Insurance Fund (SUVA), USC NIEHS Centre (grant code: 5P30 ES07048); Bergen, Norway: Norwegian Research Council, Norwegian Asthma and Allergy Association (NAAF), Glaxo Wellcome AS, Norway Research Fund; Erfurt, Germany: GSF-National Research Centre for Environment and Health, Deutsche Forschungsgemeinschaft (DFG) (grant code: FR 1526/1-1); Galdakao, Spain: Basque Health Dept; Gothenburg, Sweden: Swedish Heart Lung Foundation, Swedish Council for Working Life and Social Research (FAS), Swedish Cancer and Allergy Foundation; Grenoble, France: Programme Hospitalier de Recherche Clinique-DRC de Grenoble 2000 no. 2610, Ministry of Health, Direction de la Recherche Clinique, Ministere de l'Emploi et de la Solidarite, Direction Generale de la Sante, CHU de Grenoble, Comite des Maladies Respiratoires de l'Isere; Hamburg, Germany: GSFNational Research Centre for Environment and Health, Deutsche Forschungsgemeinschaft (DFG) (grant code MA 711/4-1); Ipswich and Norwich, UK: Asthma UK; Huelva, Spain: Fondo de Investigaciones Santarias (FIS) (grant codes: 97/0035-01, 99/0034-01 and 99/0034-02); Oviedo, Spain: Fondo de Investigaciones Santarias (FIS) (grant codes: 97/0035-01, 99/0034-01 
and 99/0034-02); Paris, France: Ministere de l'Emploi et de la Solidarite, Direction Generale de la Sante, UCB-Pharma (France), Aventis (France), Glaxo France, Programme Hospitalier de Recherche Clinique-DRC de Grenoble 2000 no. 2610, Ministry of Health, Direction de la Recherche Clinique, CHU de Grenoble; Pavia, Italy: GlaxoSmithKline Italy, Italian Ministry of University and Scientific and Technological Research (MURST), Local University Funding for Research 1998 and 1999 (Pavia, Italy); Tartu, Estonia: Estonian Science Foundation; Turin, Italy: ASL 4 Regione Piemonte (Italy), AO CTO/ICORMA Regione Piemonte (Italy), Italian Ministry of University and Scientific and Technological Research (MURST), GlaxoSmithKline Italy; Umeå, Sweden: Swedish Heart Lung Foundation, Swedish Foundation for Health Care Sciences and Allergy Research, Swedish Asthma and Allergy Foundation, Swedish Cancer and Allergy Foundation; Uppsala, Sweden: Swedish Heart Lung Foundation, Swedish Foundation for Health Care Sciences and Allergy Research, Swedish Asthma and Allergy Foundation, Swedish Cancer and Allergy Foundation; Verona, Italy: University of Verona, Italian Ministry of University and Scientific and Technological Research (MURST), GlaxoSmithKline Italy; USA: Dept of Health, Education and Welfare Public Health Service (grant code: \#2 S07RR05521-28)

We would like to thank the field staff and all those who participated in the setting up of the study and in the various aspects of the examinations at all centres for their invaluable contribution to the success of the ECRHS. We are indebted to all the participants, without whom the study would not have been possible.

Principal investigators and senior scientific team members are as follows. M. Abramson, R. Woods, E.H. Walters, F. Thien and G. Benke (Melbourne, Australia); P. Vermeire, J. Weyler, M. Van Sprundel and V. Nelen (South Antwerp and Antwerp City, Belgium); R. Jogi and A. Soon (Tartu, Estonia); F. Neukirch, B. Leynaert, R. Liard and M. Zureik (Paris, France), I. Pin and J. Ferran-Quentin (Grenoble, France); J. Heinrich, M. Wjst, C. Frye and I. Meyer (Erfurt, Germany); T. Gislason (Reykjavik, Iceland); M. Bugiani, P. Piccioni, A. Carosso, W. Arossa, E. Caria, G. Castiglioni, E. Migliore, C. Romano, D. Fabbro, G. Ciccone, C. Magnani, P. Dalmasso, R. Bono, G. Gigli, A. Giraudo, M.C. Brussino, C. Bucca and G. Rolla (Turin, Italy), R. de Marco, G. Verlato, E. Zanolin, S. Accordini, A. Poli, V. Lo Cascio and M. Ferrari (Verona, Italy), A. Marinoni, S. Villani, M. Ponzio, F. Frigerio, M. Comelli, M. Grassi, I. Cerveri and A. Corsico (Pavia, Italy); J. Schouten (Groningen, the Netherlands); A. Gulsvik, E. Omenaas, C. Svanes and B. Laerum (Bergen, Norway); J.M. Antó, J. Sunyer, M. Kogevinas, J.P. Zock, X. Basagana, A. Jaen and F. Burgos (Barcelona, Spain), J. Maldonado, A. Pereira and J.L. Sanchez (Huelva, Spain), J. Martinez-Moratalla Rovira and E. Almar (Albacete, Spain), N. Muniozguren and I. Urritia (Galdakao, Spain), F. Payo (Oviedo, Spain); C. Janson, G. Boman, D. Norback and M. Gunnbjornsdottir (Uppsala, Sweden), K. Toren, L. Lillienberg and A. Dahlman-Höglund (Gothenburg, Sweden); E. Norrman, M. Soderberg, K. Franklin, B. Lundback, B. Forsberg and L. Nystrom (Umeå, Sweden); N. Künzli, B. Dibbert, M. Hazenkamp, M. Brutsche and U. Ackermann-Liebrich (Basel, Switzerland); P. Burney, S. Chinn and D. Jarvis (London, UK), D. Jarvis and B. Harrison (Norwich, UK), D. Jarvis, R. Hall and D. Seaton (Ipswich, UK); M. Osborne, S. Buist, W. Vollmer and L. Johnson (Portland, OR, USA).

\section{References}

1 Torén K, Blanc PD. Asthma caused by occupational exposures is common - a systematic analysis of estimates of the population-attributable fraction. BMC Pulm Med 2009; 9: 7.

2 Henneberger PK, Redlich CA, Callahan DB, et al. An official American Thoracic Society statement: workexacerbated asthma. Am J Respir Crit Care Med 2011; 184: 368-378.

Wenzel SE. Asthma: defining of the persistent adult phenotypes. Lancet 2006; 368: 804-813.

4 Bousquet J, Mantzouranis E, Cruz AA, et al. Uniform definition of asthma severity, control, and exacerbations: document presented for the World Health Organization Consultation on Severe Asthma. J Allergy Clin Immunol 2010; 126: 926-938.

5 Le Moual N, Siroux V, Pin I, et al. Asthma severity and exposure to occupational asthmogens. Am J Respir Crit Care Med. 2005; 172: 440-445.

6 Jacquemin B, Kauffmann F, Pin I, et al. Air pollution and asthma control in the Epidemiological study on the Genetics and Environment of Asthma. J Epidemiol Community Health 2012; 66: 796-802.

7 Siroux V, Boudier A, Bousquet J, et al. Asthma control assessed in the EGEA epidemiological survey and healthrelated quality of life. Respir Med 2012; 106: 820-828.

8 Siroux V, Boudier A, Bousquet J, et al. Phenotypic determinants of uncontrolled asthma. J Allergy Clin Immunol 2009; 124: 681-687.

9 Le Moual N, Varraso R, Siroux V, et al. Domestic use of cleaning sprays and asthma activity in females. Eur Respir J 2012; 40: 1381-1389.

10 Cazzoletti L, Marcon A, Janson C, et al. Asthma control in Europe: a real-world evaluation based on an international population-based study. J Allergy Clin Immunol 2007; 120: 1360-1367.

11 O'Byrne PM, Reddel HK, Eriksson G, et al. Measuring asthma control: a comparison of three classification systems. Eur Respir J 2010; 36: 269-276.

12 Miedinger D, Neukomm E, Chhajed PN, et al. The use of the Asthma Control Test in general practice and its correlation with asthma control according to the GINA guidelines. Curr Med Res Opin 2011; 27: 2301-2308.

13 Kogevinas M, Zock JP, Jarvis D, et al. Exposure to substances in the workplace and new-onset asthma: an international prospective population-based study (ECRHS-II). Lancet 2007; 370: 336-341.

14 Burney PG, Luczynska C, Chinn S, et al. The European Community Respiratory Health Survey. Eur Respir J 1994; 7: 954-960.

15 Janson C, Anto J, Burney P, et al. The European Community Respiratory Health Survey: what are the main results so far? European Community Respiratory Health Survey II. Eur Respir J 2001; 18: 598-611.

16 The European Community Respiratory Health Survey II. Eur Respir J 2002; 20: 1071-1079.

17 Quanjer PH, Tammeling GJ. Summary of recommendations. Bull Eur Physiopathol Respir 1983; 19: 7-10.

18 de Marco R, Marcon A, Jarvis D, et al. Prognostic factors of asthma severity: a 9-year international prospective cohort study. J Allergy Clin Immunol 2006; 117: 1249-1256.

19 Kennedy SM, Le Moual N, Choudat D, et al. Development of an asthma specific job exposure matrix and its application in the epidemiological study of genetics and environment in asthma (EGEA). Occup Environ Med 2000; 57: $635-641$ 
Pekkanen J, Lampi J, Genuneit J, et al. Analyzing atopic and non-atopic asthma. Eur J Epidemiol 2012; 27: 281-286. Henneberger PK, Mirabelli MC, Kogevinas M, et al. The occupational contribution to severe exacerbation of asthma. Eur Respir J 2010; 36: 743-750.

22 Kromhout H, Vermeulen R. Application of job-exposure matrices in studies of the general population. Some clues to their performances. Eur Respir Rev 2001; 12: 80-90.

23 de Vocht F, Zock JP, Kromhout H, et al. Comparison of self-reported occupational exposure with a job exposure matrix in an international community-based study on asthma. Am J Ind Med 2005; 47: 434-442.

24 Olivieri M, Mirabelli MC, Plana E, et al. Healthy hire effect, job selection and inhalation exposure among young adults with asthma. Eur Respir J 2010; 36: 517-523.

25 Mazurek JM, Schleiff PL, Henneberger PK. Is childhood asthma associated with educational level and longest-held occupation? Am J Epidemiol 2012; 175: 279-288.

26 Malo JL. Asthma may be more severe if it is work-related. Am J Respir Crit Care Med 2005; 172: 406-407.

27 de Marco R, Locatelli F, Cerveri I, et al. Incidence and remission of asthma: a retrospective study on the natural history of asthma in Italy. J Allergy Clin Immunol 2002; 110: 228-235.

28 Burgess JA, Matheson MC, Gurrin LC, et al. Factors influencing asthma remission: a longitudinal study from childhood to middle age. Thorax 2011; 66: 508-513.

29 Hansen CL, Baelum J, Skadhauge L, et al. Consequences of asthma on job absenteeism and job retention. Scand J Public Health 2012; 40: 377-384.

30 Fishwick D, Barber CM, Bradshaw LM, et al. Standards of care for occupational asthma: an update. Thorax 2012; 67: 278-280.

31 Garcia-Aymerich J, Varraso R, Antó JM, et al. Prospective study of physical activity and risk of asthma exacerbations in older women. Am J Respir Crit Care Med 2009; 179: 999-1003.

32 Wang TN, Lin MC, Wu CC, et al. Risks of exposure to occupational asthmogens in atopic and nonatopic asthma: a case-control study in Taiwan. Am J Respir Crit Care Med 2010; 182: 1369-1376.

33 Ghosh RE, Cullinan P, Fishwick D, et al. Asthma and occupation in the 1958 birth cohort. Thorax 2013; 68: 365-371.

34 Centers for Disease Control and Prevention. Work-related asthma - 38 states and District of Columbia, 2006-2009. MMWR Morb Mortal Wkly Rep 2012; 61: 375-378. 